The GLID method: Moving from design features to underlying values in co-design Peer-reviewed author version

VAN MECHELEN, Maarten; Derboven, Jan; Laenen, Ann; WILLEMS, Bert; Geerts, David \& Vanden Abeele, Vero (2017) The GLID method: Moving from design features to underlying values in co-design. In: INTERNATIONAL JOURNAL OF HUMAN-COMPUTER STUDIES, 97, p. 116-128.

DOI: 10.1016/j.ijhcs.2016.09.005

Handle: http://hdl.handle.net/1942/23079 


\section{The GLID Method: Moving From Design Features to Underlying Values in Co-design}

First authors:

- Maarten Van Mechelen

Meaningful Interactions Lab, KU Leuven - iMinds

Parkstraat 45 box 3605, 3000 Leuven, Belgium

PXL-MAD, PXL University College

Elfde-Liniestraat 24, B-3500 Hasselt, Belgium

Maarten.vanmechelen@kuleuven.be

- Jan Derboven

Meaningful Interactions Lab, KU Leuven - iMinds

Parkstraat 45 box 3605, 3000 Leuven, Belgium

Jan.Derboven@kuleuven.be

Co-authors:

- Ann Laenen

Department of Digital Arts, University of Malta

Msida MSD 2080, Malta

Ann.laenen@um.edu.mt

- Bert Willems

PXL-MAD, PXL University College

Elfde-Liniestraat 24, B-3500 Hasselt, Belgium

Faculty of Architecture \& Arts, Hasselt University

Agoralaan, building D, B-2590 Diepenbeek, Belgium

Bert.willems@pxl.be

- David Geerts

Meaningful Interactions Lab, KU Leuven - iMinds

Parkstraat 45 box 3605, 3000 Leuven, Belgium

David.geerts@kuleuven.be

- Vero Vanden Abeele

e-Medialab, KU Leuven

Vesaliusstraat 13, 3000 Leuven, Belgium

Vero.vandenabeele@kuleuven.be 


\begin{abstract}
In this paper, we present the GLID method to integrate verbal, material and other co-design outcomes in a structured and coherent analysis. GLID aims to increase internal rigor and transparency in Participatory Design practices and wants to go beyond the surface level of ideas, by identifying participants' values embedded in co-design outcomes. We discuss GLID's theoretical groundings in multimodality and a values-led approach to Participatory Design, and present a case study with primary school children. This case study demonstrates how the different stages of the GLID method can be applied in practice. Based on the case study, we reflect on how GLID contributes to a holistic, situated and more empathic understanding in co-design practices.
\end{abstract}

\title{
KEYWORDS
}

Participatory design, co-design, values, multimodal analysis, means-end theory, design methods

\section{INTRODUCTION}

Participatory Design (PD) is often described as a set of theories, practices and studies related to the design of technology, aiming to give those that will ultimately be impacted by the technology a voice in its design (Muller, 2002; Schuler and Namioka, 1993). Although PD lacks a strict definition or set of rules, PD aims at establishing partnerships with future users and other relevant stakeholders. Important principles to establish these partnerships are the sharing of decision-making power and establishing a process of mutual learning (Bratteteig et al., 2013). To this end, different techniques that focus on telling, making, and enacting (Brandt et al., 2013) are used to assist participants in analyzing their experiences and giving meaning to them (Veale, 2005). Rather than extracting knowledge from participants, PD aims to co-construct knowledge and shed light on how people engage in world making in their current and future lives. Moreover, in PD, future users are typically involved in the creation of the technological artifact and the practices surrounding it (Bratteteig et al., 2013).

In this article, we focus on one specific way to engage in making activities with future users. Specifically, we focus on the use of co-design with children. Co-design techniques are used at the early, fuzzy stages of design to collectively explore and express future ways of living (Sanders and Stappers, 2008). The basic principle is to guide participants in small steps to construct designerly artifacts with $2 \mathrm{D}$ and $3 \mathrm{D}$ visual components that are often ambiguous in 
nature. Afterwards, the participants explain what they have made and why. These stories are then analyzed to inform and inspire the design process (Sleeswijk Visser et al., 2005).

Under the influence of PD, the role of children in design processes has changed tremendously (Read and Markopoulos, 2013). Whereas children were initially involved passively as technology users, their role was gradually broadened to that of active participants using a variety of co-design techniques (e.g., Dindler et al., 2005; Druin, 1999; Gielen, 2008; Horton et al., 2012; Moser, 2012; van Doorn et al., 2013). Nevertheless, it has been acknowledged that it is not easy to involve children as design partners in open-ended, future directed work (Scaife and Rogers, 1999).

The particular challenge that will be addressed in this paper is how to analyze children's contributions in co-design activities. Whereas some authors stick to a descriptive analysis (descriptive perspective), others take a more interpretative stance by looking at deeper levels of knowledge or values embedded in co-design outcomes (knowledge perspective). Within the latter perspective, two shortcomings can be identified: (1) a unilateral focus on the verbal explanation while neglecting the material dimensions of co-design artifacts, and (2) a lack of transparency when interpreting children's contributions. To address these shortcomings, the GLID method is presented, aiming to integrate the material dimensions of co-design artifacts and their verbal explanation in a structured analysis. The method goes beyond a descriptive analysis of children's ideas and aims to identify the values embedded in co-design outcomes.

This paper is structured as follows. In Section 2, we present the theoretical background of our work in co-design and multimodality. Afterwards, we present the GLID method in detail in section 3. To illustrate this method, we present a case study with primary school children in sections 4 and 5. Finally, we conclude the paper with a discussion of how GLID contributes to PD research. 


\section{RELATED WORK}

\subsection{INTERPRETING CO-DESIGN OUTCOMES}

\subsection{DESCRIPTIVE VERSUS KNOWLEDGE PERSPECTIVE}

The challenge of interpreting children's contributions resulting from co-design activities traces back to Scaife and colleagues' groundbreaking work in the late 90s (Scaife et al., 1997). They were among the first to give children a more active role in technology design, but, at the same time, acknowledged that this was not without difficulties. Compared to adults, children use different conceptual frameworks and terminology, which makes it difficult to understand the exact meaning of what a child is trying to say. In addition, although children come up with many wonderful suggestions, their ideas are often unworkable in computing terms or may conflict with educational goals (Scaife and Rogers, 1999). This problem of how to deal with children's contributions resulting from co-design activities has been a topic of much debate since then in the Child Computer Interaction $(\mathrm{CCl})$ community.

Broadly speaking, a distinction can be made between researchers looking for inspiration in the form of workable design ideas (i.e., taking a descriptive perspective) (e.g., Druin, 1999; Guha et al., 2013; Knudtzon et al., 2003; Mazzone et al., 2008; Read et al., 2014), and researchers that take a more interpretative stance by looking beyond the surface level of children's ideas to deduce knowledge embedded in co-design outcomes (i.e., taking a knowledge perspective) (Dindler et al., 2010; Frauenberger et al., 2012; Gielen, 2008, 2007; van Doorn et al., 2013). If there is not yet a well-defined design problem, approaches that fall under the knowledge perspective may be more appropriate as they provide researchers with profound insights in what drives and motivates children. In later design stages, the descriptive perspective may be preferable as the focus will have shifted from problem to solution finding. At this point, researchers may be more interested in quickly developing one or more prototypes based on a descriptive analysis of children's ideas, focusing on functional elements (e.g. product features) and aesthetic characteristics. In this paper, we focus on the knowledge perspective, presenting a method to help researchers at the early, fuzzy stages of design in their analysis of children's contributions.

Within the knowledge perspective, different types of knowledge can be revealed relying on co-design techniques. Sanders (Sanders, 2002, 1992; Sanders and Simons, 2009), for instance, argues that the act of making in co-design activities enables participants to reflect 
upon their experiences and express deeper levels of knowledge that would not have surfaced without such concrete materials. With deeper levels of knowledge she refers to people's tacit and latent needs. These needs cannot readily be expressed in words, as they are typically future needs that are difficult to identify in the present (Polanyi, 1983 as cited in Sanders, 1999). To unravel these deeper levels of knowledge, Sanders (1999) focuses on the story that comes along with the co-designed artifact: "Every artifact tells a story and so we typically ask the creator of the artifact to tell us that story." A common approach to analyze these stories is to center on identifying the themes that occur most frequently in transcripts of participants' verbal explanations (Sanders and William, 2001). These recurring themes are believed to reflect participants' tacit and latent needs.

Within the knowledge perspective, other researchers have focused on using co-design techniques to elicit values, a particular kind of knowledge (e.g., Halloran et al., 2009; Iversen et al., 2010). Our method fits within this subcategory and aims to deduce children's values embedded in co-design outcomes. The concept of value has been used in psychology to explain the motivational basis of attitudes and behavior. Rokeach (1973), for instance, defines a value as "an enduring prescriptive or proscriptive belief that a specific end state of existence or specific mode of conduct is preferred to an opposite or converse end state or mode of conduct". Although Sanders (Sanders, 2000, 1992) does not explicitly use the term values, her conception of tacit and latent needs does not seem that different. Just as values, tacit and latent needs are relatively stable and critical motivators for participants' attitudes and behavior (Rokeach, 1973; Schwartz, 1992).

Focusing on values (e.g. transparency, benevolence, autonomy and privacy) fits within a broader trend in Human-Computer Interaction $(\mathrm{HCl})$ to address the design of technology by focusing on what endures beyond interaction, that is, the outcomes and lasting impacts, and not by the ease-of-use and contextual fit alone. This has led to a proliferation of design approaches that have concerned themselves with values (e.g., Cockton, 2004; Fleischmann, 2014; Friedman et al., 2006; Iversen and Leong, 2012; Sengers et al., 2005). What most of these approaches have in common is that they hold an interactional position on the relation between values and technology: they see values as neither inscribed into technology nor as simply transmitted by social forces, it works both ways (see also, for instance, Bijker et al., 1985). Since technology cannot be considered to be value-neutral, the underlying idea is 
that the values of those impacted by technology should be taken into account throughout the design process.

PD holds a similar position on the relation between values and technology and has been a highly values-led design approach from its very beginnings. However, compared to other values-led design approaches (e.g., Cockton, 2004; Fleischmann, 2014; Friedman et al., 2006), PD differs in that values are not seen as something that is 'applicable' to design after being identified first. Rather, the values at stake and the artifacts being designed mutually influence each other as the design process unfolds. This situated view on values implies that the same values can be appropriate in one context but problematic in another and that there is no single interpretation of values that serves all situations (JafariNaimi et al., 2015). Moreover, knowledge generation in PD is seen as a dialogic process that is strongly situated and mediated by participants' personal values (Frauenberger et al., 2015). The co-design process is regarded as a negotiation of values that the participants bring to the table or which emerge from the collaborative experience (Iversen et al., 2012, 2010; Iversen and Leong, 2012).

With co-design techniques, values can be elicited both on an individual and collective level. On an individual level, the act of making helps to raise awareness about one's own values and value tradeoffs, because reflection about the design challenge is not detached from action, i.e. making a solution for a specific context. On a collective level, these personal values are simultaneously negotiated with other participants, either implicitly or explicitly. This may in turn influence participants' personal value systems and reframe the design problem. For example, in a series of co-design activities about how to balance the risks and opportunities of social media, children initially valued free exploration and social recognition of their peers, whereas parents emphasized online security. Throughout the activities, these emerging values evolved, and, eventually, the team developed a concept for a parental mediation application. Rather than to restrict internet access, the application aims to increase children's social media literacy through peer learning and open communication with their parents (Donoso et al., 2014). Iversen and colleagues (2010) refer to this process as the emergence, development and grounding of values into one or more artifacts and, ideally, in the participants' future practice. This joint sensemaking or collective reflection in action is at the heart of PD (Ehn, 1993). A core task for design researchers is to mediate this process and facilitate dialogue between participants. Since not all values emerge by explicit means, care- 
ful observation and interpretation of the co-design artifacts are required (Iversen et al., 2010).

\subsubsection{KNOWLEDGE DISCOVERY AND ANALYSIS}

Embedded knowledge (e.g. tacit and latent needs, values) is often deduced by focusing on the verbal component of a co-design outcome as the main unit of analysis, whereas the material dimensions are somewhat neglected (Sanders, 1999; Sleeswijk Visser et al., 2005; Stappers and Sanders, 2003). This focus on participants' verbal explanation assumes that codesign artifacts are regarded as a transparent means to access embedded knowledge. Piper and Frankham (2007) have referred to this approach as an 'uncritical celebration of representation', emphasizing that verbal explanations should be analyzed in relation to the visual materials and the role of the researcher in producing and presenting these materials (Piper and Frankham, 2007). Similarly, Buckingham (2009) has used the term 'naïve empiricism', arguing that data from creative research cannot be taken at face value: "these data need to be analyzed with special attention for its visual dimensions". He continues that we need to be wary of the idea that any particular method necessarily allows participants a direct or transparent means of expressing themselves or having their voices heard. Instead of falling back on verbal accounts or a descriptive analysis, methods are needed that can deal specifically with the visual dimensions of such material (Buckingham, 2009). Both 'verbal outcomes' (i.e., what participants say or write about their creation) and 'material outcomes' (i.e., the co-design artifact, constructed in 3D) should be analyzed and interpreted in relation to each other (Derboven et al., 2015).

Like Piper and Frankham, and Buckingham, we endorse the view that material co-design artifacts and their verbal explanations are always 'constructed' and therefore do not give access to deeper levels of knowledge (e.g., Sanders, 2002, 1992; Sanders and Simons, 2009) or values (e.g., Halloran et al., 2009; Iversen et al., 2010) in a direct and unmediated way. However, the current literature on PD offers little guidance on how to analyze and interpret verbal and material outcomes in relation to each other, and in a structured and transparent way. To fill this gap, Brandt and colleagues have already called for more research on how to analyze data generated by making, telling and enacting activities, including generative techniques such as co-design (Brandt et al., 2013). 
In addition, Frauenberger and colleagues have argued for more internal rigor and accountability in PD practices, be it not in a positivistic or reductionist sense. In line with its roots in social constructivism and phenomenology, more holistic and interpretative approaches are needed to analyze participants' contributions in PD, aiming for systematic and critical reflection (Frauenberger et al., 2015; Lee, 2014). This is especially true when involving children as design partners. When it comes to abstract concepts such as values, children may have a difficult time verbalizing their thoughts (Piaget, 1970). However, since values are critical motivators of attitudes and behavior (Rokeach, 1973; Schwartz, 1992), the way in which children approach a design challenge tells us something about their values, albeit implicitly. Deducing these values requires a process of interpretation and rigorous attention for both the material characteristics of co-designed artifacts and their verbal explanation. This paper offers a method to demystify this process of interpretation and, ultimately, arrive at children's values embedded in co-design outcomes.

\subsection{Multimodal Semiotics}

\subsubsection{Analyzing Communicative Modes and Metafunctions}

Multimodal semiotics (also known as 'multimodality', see e.g. (Jewitt, 2013, 2010) is a semiotic approach that finds its origins in the functional linguistics of (Halliday, 1978), and the social semiotics of e.g. Hodge and Kress, (1988). As a semiotic approach, multimodality concentrates on how communication is structured and presented. Specifically, multimodality has proven its usefulness in the analysis of digital technologies (Jewitt, 2013; Zhao et al., 2014), and even in the analysis of a specific PD case with children with Autistic Spectrum Disorder (Malinverni et al., 2016). The GLID method presented below builds on this work, providing a structured method to integrate the material dimensions of co-design artifacts and their verbal explanation in a structured analysis. The method goes beyond a descriptive analysis of children's ideas and aims to identify the values embedded in co-design outcomes. In our approach, two basic assumptions of multimodality are relevant for the analysis of codesign outcomes: the assumption that all communication consists of various communicative 'modes' (e.g., written, verbal, visual), and the assumption that all communication can be analyzed in terms of three 'metafunctions'.

The first assumption is that communication is more than only the use of language: communication always includes several 'modes' that contribute to the meaning of a message (Kress, 2010). Modes, in this framework, can be seen as 'channels' of representation or communica- 
tion (such as writing, image, sound) that collaborate in communicating messages (Jewitt, 2013). This analysis of different modes emphasizes that each mode has different affordances: specific characteristics that make them suitable for communicating specific information (Jewitt, 2010). For example, while text is more suitable for narratives, images can be easier to communicate moods and emotions. Similarly, in co-design outcomes, various modes of communication are used, such as verbal communication (spoken or written), visual communication, body language, etc. As all of these specific modes communicate different information, multimodality is a useful approach that allows for an integration of these modes in one holistic study. For the analysis of co-design outcomes, we use a division in general modes of communication, such as 'verbal' (the participants' explanations, either written or oral) and 'material' (artifacts, including their visual and tangible features) modes.

The second assumption relies on a distinction between the different functions that every communication fulfills. In line with its social semiotic origins, multimodality identifies three basic functions of communication, called 'metafunctions'. These 'metafunctions' analyze 1) what is presented (which reality is being represented?), 2) who is involved (how are social relationships constructed between actors in this reality), and 3) how is the communication structured (how is the message structured as a coherent entity that makes sense?).

The multimodal analysis into communicative modes and metafunctions aims to offer insights into how communication is structured, and how it presents a specific view on reality. Such "socially constructed knowledges of some aspect of reality" (Van Leeuwen, 2005: 94) are called 'discourse', in multimodal semiotic terminology. In every communication, reality is represented in a selective, socially constructed way. Specific aspects of reality are included and arranged in a particular way, and as such, each selection indirectly represents a set of socially shared values (Barker and Galasinski, 2001). Therefore, the multimodal analysis will play a central role in the GLID method described below, as it is instrumental in making explicit how a specific view on reality is constructed in co-design outcomes.

\subsubsection{Multimodal Semiotics, Discourse and VAlues}

In the GLID method, we will use multimodal semiotics to analyze the discourse embedded in the co-design outcomes. This analysis of discourse will lead us to an insight into the values that underpin the co-design participants' outcomes. In order to clarify our use of a multimodal, semiotic approach for the analysis of values in PD, we will complement it with a brief discussion of means-end theory. According to means-end theory, people choose a product 
because it contains certain attributes (the means) that are instrumental to achieve desired consequences or benefits, which, in turn, fulfill certain values (the ends) (Gutman, 1982; Reynolds and Gutman, 1988). This theory has been used in $\mathrm{HCl}$ to analyze how technology relates to user values (e.g., Vanden Abeele et al., 2011; Zaman and Vanden Abeele, 2010), and also stresses social constructedness in its discussion of product use (Reynolds and Gutman, 1988).

At first sight, there are obvious differences in approach, terminology, and intellectual roots between multimodality and means-end theory. While means-end theory describes how surface features are related to underlying values, multimodality describes how surface features combine into specific discourses (e.g., Van Leeuwen, 2005). Values and discourse are not interchangeable in PD, but we do argue that most values are embedded implicitly in the way participants represent reality in a selective way. Through the analysis of discourse (i.e., analyzing the situations described in the co-design outcomes, and the way they change the current status quo), it becomes possible to access the social value systems embedded in it. In means-end theory, the analysis of product features (also termed attributes) and their consequences progressively 'drills down' to an analysis of underlying values. A similar procedure can also be found in multimodality, where the analysis of different modes of communication and metafunctions leads to an analysis of discourse. As such, both methods can be used to 'drill down' to underlying values or discourse mediated through the intermediate steps of either consequences or metafunctions.

\begin{tabular}{|c|c|}
\hline MEANS-END THEORY & MULTIMODAL SEMIOTICS \\
\hline $\begin{array}{l}\text { Product features (cf. attributes) } \\
\downarrow\end{array}$ & Product features \\
Direct and indirect \\
consequences or benefits & $\begin{array}{l}\text { Communicative modes and } \\
\text { metafunctions }\end{array}$ \\
$\downarrow$ & $\downarrow$ \\
Values & Discourse \\
\hline
\end{tabular}

Figure 1: Means-end theory and multimodal semiotics 'drill down' to respectively values and discourse in a similar way. 
Inspired by applications of means-end theory in $\mathrm{HCl}$ (e.g., Vanden Abeele et al., 2011;

Zaman and Vanden Abeele, 2010), progressively 'drilling down' to an analysis of underlying values, we argue that multimodality can be used in a similar way to analyze co-design outcomes (see Figure 1). The combination of the analysis into communicative modes and metafunctions (see 2.2.1) makes multimodality well-suited for an integrated analysis of verbal, material and other co-design outcomes that reaches out to underlying discourse and, ultimately, value orientations. As such, multimodality can enable design researchers to uncover the discourse and values underpinning co-design outcomes. In the next section, we will describe this 'drilling down' to underlying values in detail, as we describe the various analytic stages of the GLID method.

\section{DESCRIPTION OF THE GLID METHOD}

Inspired by a values-led approach to PD and multimodal semiotics and, the multimodal GLID method consists of four broad stages: Grounding the analysis, Listing design features, Interpreting orientation and organization, and Distilling discourse and values (see Figure 2).

\subsection{GROUNDING THE ANALYSIS}

What

Inventorying the set of initial ideas that came up during the sessions. Tracing the evolution from initial ideas to final outcomes, and situating the final outcomes against the background of their origins.

\section{Why}

Situating co-design outcomes in its origins can clarify why certain (design) decisions were made. Tracing the origins can help to contextualize the eventual outcome, especially when that outcome proves to be ambiguous in some respect.

Apart from grounding the analysis, it can be enlightening to see how the initial ideas have been transformed during the co-design process and how they have made it into the final outcomes. Tracing the evolution of the selected ideas can already give a first insight into the type of outcome that was targeted (Van Mechelen and Derboven, 2014). 


\section{How - Relevant Questions}

How did the co-design outcomes grow and transform into their final form? Which early, constituent ideas can be traced? Which ideas did not make it to the final outcomes?

\subsection{Listing Design FeAtures}

What

Listing design features in detail. Differentiating between different modes of communication (visual, material, etc.), and tracing which features are communicated in which modes.

\section{Why}

Listing design features provides a basic description that can be used for further, more thorough analysis. This listing of features can also provide a first insight into which features are highlighted as the most salient features, and which features have been given less attention.

This stage is based on the first of the three metafunctions in multimodality: the presentational metafunction (the terminology is based on Lemke's (2002) view on metafunctions). The presentational metafunction is related to the concrete, functional layer of designed artifacts. It is a description of the 'state-of-affairs', detailing what aspect of reality is presented in the co-design outcome. It describes what is represented, and what activities potential users or stakeholders engage in. As such, both functional (actions that can be performed) and non-functional (visual, aesthetic) aspects of the co-design outcomes are described. In means-end terminology, this is a detailed overview of the directly perceivable attributes (material, visible product features) and their functional consequences (immediate tangible benefits: the purposes they serve and the interactions they allow).

Furthermore, combined with the first step (Grounding the Analysis), various design features can already be traced back to their origins. This additional background on the design features provides the basis for the analysis described below.

\section{How - Relevant Questions}

What do the co-design outcomes consist of? Which features do they have? Which features stand out? Which actors and objects participate in the reality presented through the codesign outcomes? Which modes are present in the co-design outcomes? In which mode are the features communicated? What are their functions? 


\subsection{INTERPRETING ORIENTATION AND ORgANIZATION What}

In this stage, the analysis focuses on how the co-design outcomes are presented as a coherent whole, projecting a reality with specific social relationships between various actors.

\section{Why}

This step is based on the two last metafunctions identified by multimodality: the orientational and organizational metafunctions.

- Orientational: This analysis focuses on contextual social relations, and therefore specifies 'attitudes' towards the state-of-affairs in the co-design outcome mentioned above. Analyzing the features' orientation determines how actors, in the reality projected by the co-design outcome, are (implicitly or explicitly) involved in the interaction with the outcome. As such, the orientational metafunction focuses on social consequences. It evaluates and positions the situation (desirable or not, necessary or obligatory, etc.) and evaluates the relationships among participants and objects (in terms of power relations, influence, etc.).

The orientational layer is especially important for PD, as it specifies how specific social situations are evaluated, offering insight in the way in which specific values are embedded. In other words, this analysis focuses on shared meanings, attitudes and relations that hint towards specific values (Lemke, 2002).

Linking multimodality with means-end theory, the orientational meaning relates to psychosocial benefits. It is an analysis of how the co-design outcome intervenes in a specific situation, and which psychological or social consequences are linked to it. These consequences embody the meaningful, alternative futures envisioned by the PD participants.

- Organizational: Analyzing the features organizationally shows how the co-design outcome as a whole is constructed as an artifact, a story or in another discursive form. Here, the focus is on how the initial co-design idea or challenge was 'translated' into a coherent outcome, integrating or contrasting different features and value orientations into a whole.

The interaction between the various modalities is important. As different modes can communicate different types of information (see also 2.2.1), it is important to analyze how different modes work together in order to communicate a message (i.e., the cohesion between modes). Do different modes confirm and reinforce each oth- 
er, or contradict each other? Are the same features present across modes presented in a similar way ('transduced' (Kress, 2010) from one mode to another), or do different modes emphasize different features?

\section{How - Relevant Questions}

- Orientational: Which actors are involved in the use of the artifact, directly and indirectly? Which stakeholders are mentioned by the co-design team and which are not? What are the relationships among these actors, and how does the artifact mediate these relationships? What are the psycho-social benefits for the different actors?

- Organizational: How was the initial co-design challenge or idea brought together into one co-design outcome? How does the outcome constitute a meaningful whole (application, tool, etc.)? How are specific messages confirmed and reinforced (highlighted) across modes? Does the analysis lead to contradictory interpretations across modes?

\subsection{Distilling Discourse AND VAlues}

\section{What}

Distilling the discourse based on the previous analytic stages. In this stage, the focus is which specific discourse is used to envision future practices and technologies, and which values this discourse represent.

\section{Why}

In this stage, the previous stages culminate in a meta-analysis of how the future practices and situations evoked in the co-design outcomes are evaluated in terms of the PD participants' underlying and negotiated values. Guided by the trajectory from initial idea to eventual co-design outcome (Grounding stage), this stage sums up how the co-design outcome represents a specific aspect of reality (Listing stage), combining various modes of communication in a coherent way (Interpreting stage: organization). Together, these elements form the specific discourse ( $a$ 'socially constructed knowledge of some aspect of reality' (Van Leeuwen, 2005)) presented in the co-design outcome. The outcome therefore represents a specific selection and configuration of that reality: e.g., social relationships between actors are always constructed in a particular way (Interpreting stage: orientation). 
As such, the meta-analysis builds on the previous analytic stages to show which specific discourse is used to envision future practices and technologies, and which values this discourse represent. This discourse is essentially a coherent synthesis of the analysis from the second and third stage. However, in this phase, the goal is to transcend the details of the specific situation described in the co-design outcome (e.g., specific functionalities - see 3.2), and move towards the values that underpin and motivate these specific, contextual details. From this discourse, specific value orientations can be deduced.

\section{How - Relevant Questions}

Which aspects of reality are included and excluded in the co-design outcomes? How are these aspects of reality evaluated? How does the artifact represent and influence this reality? With what purpose? How is it legitimated? Which set of values is communicated through this representation of reality?

\subsection{SUMMARY}

In summary, relying on GLID, design researchers are guided through a stepwise procedure for anlyzing co-design outcomes. Different modes of communication are integrated in a coherent analysis in order to 'drill down' to children's values (see figure 2). In the stages outlined above, stages 3 and 4 are the most interpretative ones. While literature on co-design already has a tradition of analyzing verbal outcomes, this is not the case for the analysis of visual, or material outcomes. This raises the question of the validity of the interpretations: are they constructed in a systematic and transparent way? This can be addressed in several ways. First, consistency among different modes can be analyzed: considering the different modes as different aspects of the same idea. While contradictions between modes are possible, in general it is the cohesion across modes that validates the analysis. The separate interpretations of different modes from stage 2 (listing design features) are brought together in one interpretation in stage 3 (interpreting orientation and organization). This unified analysis allows for an analysis of similarities and differences between various modes. For instance, the same feature can be present across modes in a similar way ('transduced' (Kress, 2010) from one mode to another), different modes can emphasize different features, etc. 


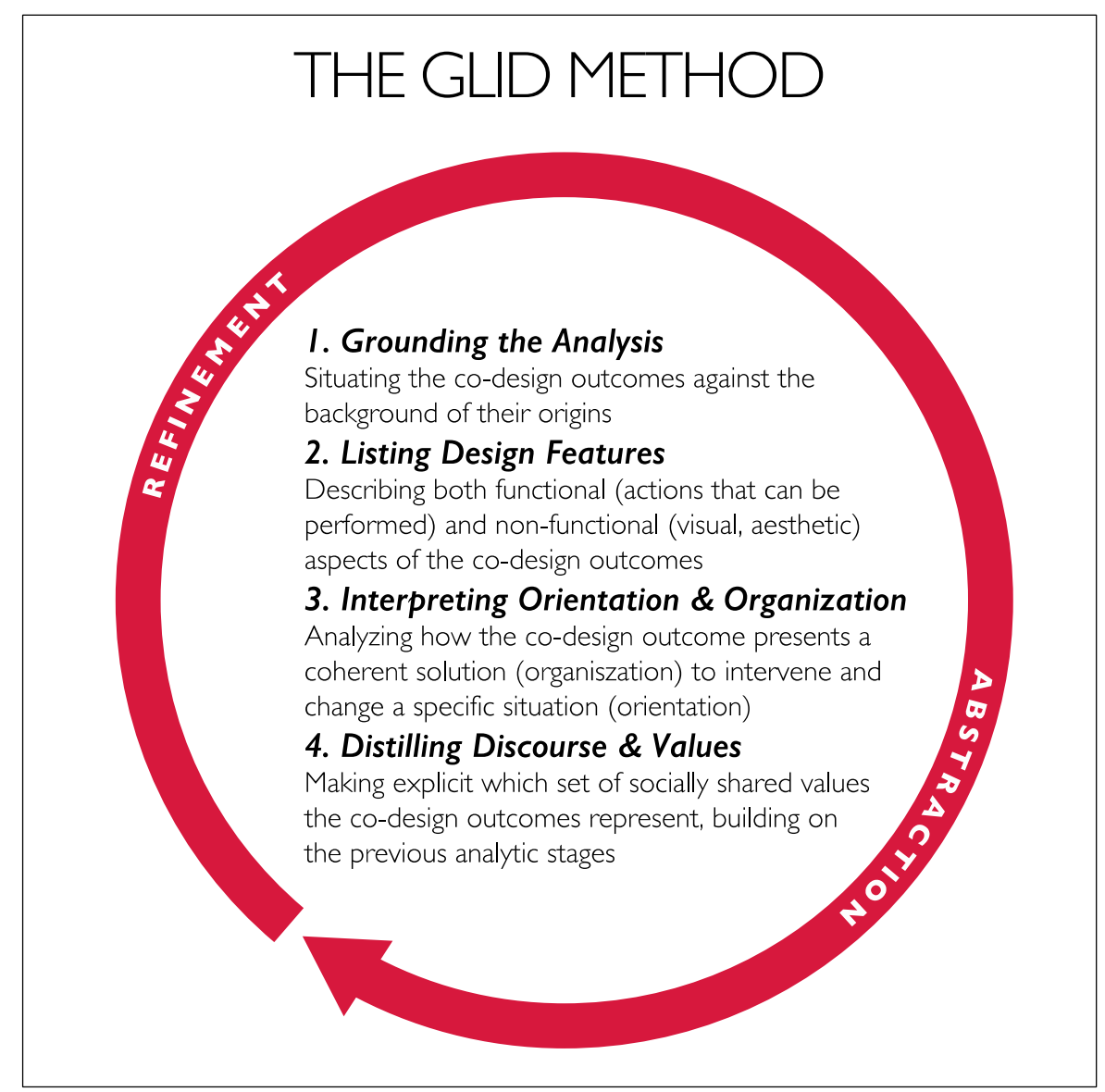

Figure 2: The four broad stages of the GLID method for analyzing co-design outcomes.

As a second validation, the interpretations of design features can be grounded in their origins. Checking the interpretations in this stage for consistency with the outcomes' origins traced in stage 1 provide additional validity. If the interpretations prove inconsistent with the origins, the co-design process itself should be examined for specific shifts in meaning and interpretation. If these shifts can be traced, the inconsistencies between the origins and the outcomes can be brought back to the co-design process itself. In this case, it is necessary to analyse why and how these shifts in meaning and interpretation have occurred. However, if no shift in meaning can be traced, the interpretations of the outcomes can be revised: in this sense, the interpretive process is iterative.

Finally, as the GLID method has been developed to analyze underlying values in co-design outcomes, it is important that researchers are aware of the values they bring to the PD process themselves. Methods to uncover these values have already been introduced in the PD literature (Frauenberger et al., 2015; Read et al., 2013; Van Mechelen et al., 2014b). Hence 
we advise to make this reflexivity explicit, perhaps as an extra step at the start of the GLID method, and certainly before step 3 and 4, when listing psycho-social benefits and analyzing the values embedded in the co-design outcomes. It is important to note to what extent the participants mimicked the researcher's values, or transcended or modified them.

\section{CASE Study Procedure}

To illustrate the GLID method, we present a case study in which 49 children aged 9 to 10 were involved in a series of co-design sessions in two schools in Flanders, Belgium. The sessions were part of a project aimed at the design of tangible, digital tools to make class groups more self-regulatory in the prevention of both traditional bullying and cyberbullying. This goal was translated into an understandable design challenge for children: what tools would improve the class atmosphere and prevent bullying? To make it more tangible, we used a fictional story of a class with a negative atmosphere as a starting point for co-design. In the story, that was read out loud when we first met the children, our own values with regard to the problem of bullying were embedded: we aspired a proactive approach that would increase children's self-regulative behavior, with the ultimate goal to create a safe environment for children. Although we started from these preliminary value orientations (prevention, increasing self-regulation) and from a broad view on what was to be designed (tangible, digital tools), these preliminary ideas were open to change. During the co-design sessions, we allowed the children's work to challenge our ideas and broaden our perspective.

Over a period of one month, two co-design sessions were organized in two primary schools (150 minutes each) preceded by a general introduction (50 minutes), resulting in three visits per school. Two of the authors were involved in the co-design sessions, each facilitating two to three teams at the same time, without intervening in the creation process. Below we will briefly describe the different sessions. For a detailed description of the co-design procedure and the prompts used in this particular case, we refer to Van Mechelen and colleagues $(2015,2014 a)$. 


\subsection{INTRODUCTION AND SENSITIZING}

When we met the children for the first time in their classroom, we explained the design challenge and we introduced a sensitizing package (Sleeswijk Visser et al., 2005) with four individual assignments. The goal of these assignments was to trigger children's reflection in a playful and creative way, and to prepare them for the co-design sessions approximately two weeks later. One of the outcomes, that is, an assignment in which they had to draw a class with a bad atmosphere, was also used to construct a fictional story to be used as a starting point for co-design.

\subsection{FIRST CO-DESIGN SESSION}

The aim of the first co-design session was to create cohesive teams and, for each team, to define two problems based on the story and the design challenge. After introducing the story, the class group was divided into gender-mixed subgroups of five children. Each team member had a special responsibility within the team (the material master, the inspiration general, the time keeper and the silence captain). These roles were visualized on badges and were divided amongst the children of the team. Next, the teams were engaged in introductory design activities (e.g. group name and logo design) to get used to working in a team and to increase social cohesion. Afterwards, the teams visualized the on a big sheet of paper (collage) and defined two design problems based on their interpretation of the story. The story was printed on cards, one for each team, as a visual reminder. When the teams were finished, they briefly presented and explained their collages to the other groups. The session ended with a short discussion about the group process and how it could be improved during the next session.

\subsection{SECOND Co-deSIGN SESSION}

The aim of the second co-design session was to design and prototype the actual tools. We first introduced the children to the concept of brainstorming, after which each team thought of different ideas of how a superman would solve the problems defined during the first session. Each idea was written on a separate sticky note and put in the middle of the table to inspire the other team members. Next, the teams grouped similar ideas together and selected two ideas for further elaboration. To build their three-dimensional prototype, the teams received a bag full of materials (e.g. scissors, cardboard, glue, ropes, aluminum dishes, etc.). Once finished, each team verbally presented their invention (see, for example, figures 3,4 
and 5), while the other teams functioned as a jury, providing constructive feedback. These presentations were recorded on video. The session ended with a short group discussion about how we would take their designs forward in the next stages of our research.

The co-design sessions resulted in various outcomes. For each group, we analyzed:

- a collage of two problematic class situations defined by the children during the first co-design session (e.g. children excluding each other from playing games);

- verbal descriptions on post-its of how a superhero would solve these problems (e.g. Spiderman capturing bad children in his web). From these solutions, the teams picked two for further elaboration;

- an artifact designed by the children that embodies the solution chosen in 2;

- transcripts of verbal presentations of the artifact.

\section{RESULTS}

\subsection{Eleven Co-Design Outcomes, Three Examples}

Within the scope of this paper, it is not possible to offer detailed analyses of all eleven artifacts and presentations created in the co-design sessions. In order to offer clear examples of our analytic procedure, we will discuss three co-design outcomes in detail. Although we were able to identify children's negotiated values in each of the eleven artifacts, these three examples were chosen for didactic reasons because of their diversity. Created in teams of five children who worked together in both sessions, the three co-design outcomes therefore represent the contributions of 15 children. These examples will make clear how artifacts and verbal information can be combined in analysis, in order to arrive at a situated understanding of the values that underpin these co-design outcomes.

\subsection{OUtCOME 1: Robot SPRIETJE}

\subsubsection{GROUNDING THE ANALYSIS}

The co-design team 'Vivalalalas' translated the design challenge in two concrete problems (see section 4.2): (1) not being kind to one another and (2) forming cliques and excluding 
others. To improve the class atmosphere, the team assumed everybody should be kind to one another and children should play together instead of forming cliques. Before the creation of the artifact, the team had various initial ideas to solve the problematic situations and improve the class atmosphere.

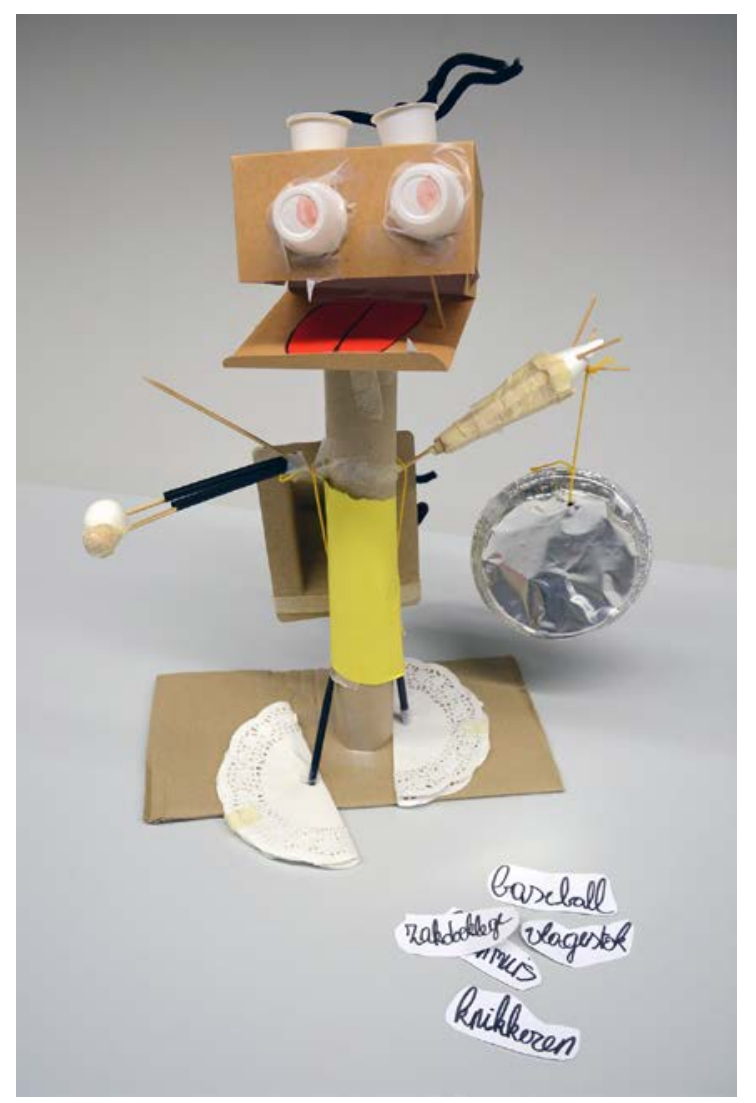

Figure 3: 'Sprietje', a DJ robot designed by team 'Vivalalas'

These ideas were analyzed and categorized in terms of our own values (prevention, selfregulation, safe environment - see Section 4). Three broad categories were created: ideas to facilitate reconciliation or prevent bullying and other problematic class situations ('positive' ideas), disciplinary, and even punishing ideas to remediate such situations ('negative' ideas), and more neutral ideas, that combined elements of the categorization above, or were difficult to categorize for other reasons. The team started out with a clear overweight of positive, preventive ideas compared to negative, disciplinary and more neutral ideas (9 versus 4 and 3). From the pool of ideas they had come up with during brainstorming, the team members collaboratively selected two ideas for further elaboration. For the first problem, not being kind to one another, the team selected a positive, preventive idea as most promising: 
"organizing a party to bring children together". For the 2 nd problem, forming cliques and excluding others, they chose a positive, preventive idea as well: "playing a game together". In the evolution from initial ideas to artifact, the negative, disciplinary ideas completely disappeared in favor of positive, preventive ideas. Further analysis of the co-design outcomes, then, can be grounded in two main characteristics: the translation of the design challenge in two concrete problems (not being kind to each other and forming cliques), and the children's generally positive, preventive attitude to solve these problems.

\subsubsection{LISTING DESIGN FEATURES}

With their original ideas in mind, the team invented robot called 'Sprietje' (see Figure 3). The co-design team associated several functionalities with their human-shaped robot, including a backpack filled with tips for games, and a drum.

Noticeable functional aspects of Sprietje include his backpack with games, his drum and drumstick. The first main functional feature, the backpack, was made visual/tangible in the form of a cardboard backpack attached to Sprietje's shoulders with ropes. The games or tips themselves, though, were not made tangible: they were mentioned during the presentation, and represented by pieces of paper with names of games written on them (e.g., baseball, play at marbles). During the presentation, the backpack feature was further elaborated upon: if children come up with a good idea themselves (e.g., games you can play with more than two people), Sprietje will collect it in his backpack. The game cards in the co-design outcome only mentioned games, and no 'tips' for a better class atmosphere. However, the 'good idea' the children mentioned during their presentation (games you can play with more than two people) suggests that their ideas about ameliorating the class atmosphere are mostly play-, game- or fun-related. Furthermore, the children mentioned in their presentation that Sprietje eats all 'bad ideas' (e.g. a game for only two participants, so others cannot join) to prevent children from excluding one another. Indeed, the robot has a large mouth, with some sharp teeth - and a large tongue.

A second main functional feature of Sprietje is his drum: the robot holds a drum in one hand and a drumstick in the other. With these attributes, Sprietje is also a DJ. The children mentioned during the presentation that the drum and the drumstick are Sprietje's tools to organize class parties. 
Sprietje's non-functional features create a distinct personality for the robot, which is reflected in the fact that the team named the robot, which was implicitly described in the participants' presentation (e.g. "he tells very good jokes"), and more explicitly visualized in the artifact itself. The robot looks funny, friendly and even somewhat rebellious (e.g. haircut, two sharp teeth, etc.). In this sense, verbal and material modes complemented each other. No punishing component was added in the visual appearance of the robot, nor in the children's presentation: when a conflict occurs, he first listens, negotiates a solution and counters the situation by telling a good joke.

\subsubsection{INTERPRETING ORIENTATION AND ORGANIZATION}

Orientationally, Sprietje acts independently from the teacher as a third person. It is a robot with agency and human-like characteristics (e.g. listening and negotiating a solution), not just a toy or a piece of technology that children can use whenever they feel the need to. Moreover, the robot represents an authority: he actively manages the classroom as a whole by guiding children's activities (e.g. eating bad ideas, organizing parties) to optimize the class atmosphere, and he takes an active role in negotiating solutions for conflicts. This active role, however, is somewhat ambiguous. On the one hand, Sprietje facilitates the process of reconciliation between children by negotiating solutions; on the other hand, he also 'eats bad ideas' and tells jokes to defuse conflicts. The latter solutions are a kind of deus ex machina solutions, in which bad ideas are thwarted before they can even present a problem (by eating them), or in which children are distracted from the conflict (through the jokes). In sum, Sprietje presents a positive authority that targets the classroom as a whole by guiding the children's activities and organizing parties. He solves conflicts instantly if he can, and facilitates reconciliation processes if necessary.

Organizationally, the figure of Sprietje represents different aspects of authority. He embodies a solution for two problematic class situations described in 5.2.1: not being kind to one another, and forming cliques and excluding others. The children's solutions to these initial problems both were collective solutions: organizing a class party, and playing a game together. Both these fun, collective solutions are shown clearly in Sprietje's material elaboration: the backpack with good ideas and games, and the drum for the class party are oriented towards the class as a collective. In semiotic terms, both solutions were 'transduced' (see (Kress, 2010) - moved from one to another mode) to the material artifact: this stresses the 
importance of this aspect of Sprietje. The targeted interventions to facilitate reconciliation, however, were not part of the solutions they initially envisioned: they were mentioned during the presentation, but did not result in specific attributes or functionalities. The only aspect of the targeted interventions hinted at in Sprietje's funny appearance is of defusing conflicts by telling jokes.

In sum, both initial, collective solutions were mentioned during the presentation, and embodied in the artifact. The targeted interventions, however were only mentioned in the presentation, and were not elaborated in the artifact. These positive robot features, and the lack of punishment show the children's generally positive, preventive attitude to solve the problems they selected.

\subsubsection{Distilling Discourse AND VALUES}

The co-design team expressed the need to focus on the class group as a whole in a 'noblame' atmosphere. The analysis of the design features already revealed that positivity, fun and humor are key: this was evidenced by the funny-looking material elaboration of Sprietje, and the children telling about how the robot can tell jokes and organize parties. This hints at a preferred strategy of prevention rather than intervention, as already hinted at in the grounding phase.

Although the robot represents an authoritative figure from an orientational perspective, it is by no means a disciplinary but rather a 'soft authority' acting as a neutral, third party. 'Hard' intervention is never necessary, due to the children's stress on 'motivated' or 'directed' forgetting. When a conflict occurs despite Sprietje's efforts for prevention, he observes and listens without judgment and quickly goes through the social process of negotiating a solution. After a while he will tell a good joke to distract the children, enabling them to move forward without looking for someone to blame: the figure of Sprietje shows that children leave no place for disciplinary punishment.

The children's solution to a bad class atmosphere, and specifically the problems of (1) not being kind to one another and (2) forming cliques and excluding others, can be found in collective, fun activities (class parties, and playing together): positive and preventive ideas that were translated and merged into the figure of Sprietje. While we started our co-design activities and analysis from values of prevention, self-regulation, and safety (safe environments), Sprietje modified and complemented our initial values in several ways. Sprietje embodies 
the children's ideas about a positive authority with a focus on values of collective fun and positivity (creating a preventive, safe environment), but de-emphasizing the role of social reconciliation processes, and leaving no place for disciplinary punishment.

\subsection{OUTCOME 2: HYPNOSIS MACHINE}

\subsubsection{GROUNDING THE ANALYSIS}

The team 'Samenwerkers' (Dutch for 'Collaborators') translated the design challenge mentioned in Section 4 in two specific problems (see section 4.2): (1) 'laughing at others' and (2) 'sad faces in class'. Instead of laughing at others, the team reasoned, children should respect each other and sad faces should be turned into happy ones. The team started out with a clear overweight of preventive, positive compared to disciplinary, negative ideas (8 versus 3). From the pool of ideas they had come up with during brainstorming, the team members collaboratively selected two ideas for further elaboration. For the 1st problem, laughing at others, the team selected a positive, preventive idea as most promising: "Batman guarantees it will not happen often". For the 2 nd problem, sad faces in class, they also chose a preventive, positive idea: "hypnotizing the teacher so she will tell funny jokes".

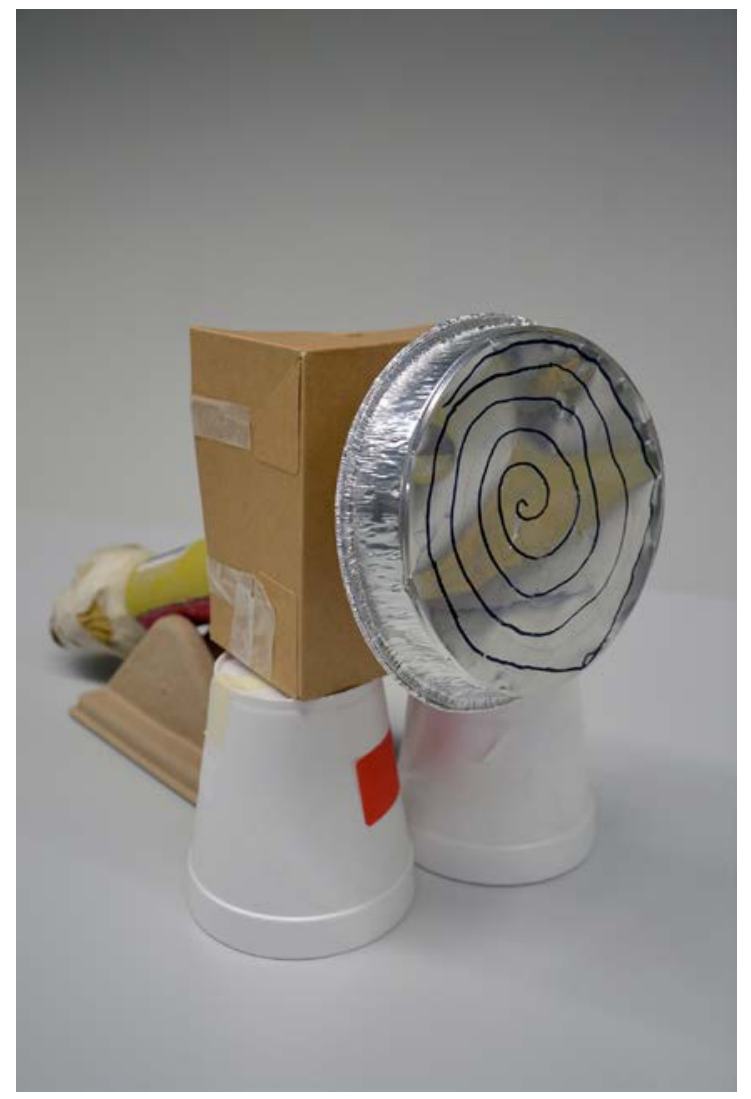

Figure 4: a hypnosis machine developed by team 'Samenwerkers' 
Further analysis of the co-design outcomes, then, can be grounded in two main characteristics. First, the team started out with a clear overweight of positive ideas, and selected two positive, preventive ideas for further elaboration. Second, in both solutions, there is a clear role for an adult figure: Batman in the first, the teacher in the second.

\subsubsection{LISTING DESIGN FEATURES}

Based on the initial ideas, the team invented the 'Hypnosis Machine' (see Figure 4), a device to be used by the children themselves. The Hypnosis Machine is an industrial looking robust tool, with an aluminum hypnosis disk with a black spiral on it. The children created the machine with much attention for functional (as opposed to aesthetic) detail, such as a robust handle, and an arrow to indicate the direction of rotation. This focus on functionality in the artifact was also evident in the way the children talked about their machine: in this sense, the verbal and material modes complemented each other. A large part of the presentation was devoted to the way the tool works, continuously pointing to specific attributes of the artifact, such as the aluminum hypnosis disk and the handle, explaining their functionalities. All non-functional features (arrows etc.) serve to explain the operation of the functional features.

In the second part of the presentation, the team moved beyond the interactive details of their prototype, and explained who would use the Hypnosis Machine. Victims can use the Hypnosis Machine to hypnotize bullies, to make them forget that they are bullies so they will not laugh at them again. Sad children, on the other hand, can use the machine to hypnotize themselves as a way to become happy. Overall, however, the co-design team focused on how the tool should be operated, in line with the industrial equipment-like look of the Hypnosis Machine.

\subsubsection{INTERPRETING ORIENTATION AND ORGANIZATION}

Orientationally, the co-design team explained how the Hypnosis Machine allows sad children or victims of bullying to do something about their own situation. Self-regulation, and interaction between individuals (victim and perpetrator) is key here. The machine focuses on bullies and victims but not on bystanders or the class group as a whole, although the team, in their presentation, mentioned once that a random classmate could use the machine to hypnotize a sad child to make him or her happy again. 
This orientational function of the Hypnosis Machine was not evident in its material elaboration: the looks of the tool do not give information on its potential users. Its industrial looks (see above) make the tool not clearly positively or negatively oriented, but very robust nonetheless. If the machine was only used by victims to hypnotize bullies, it could be interpreted as a punishment tool: the victim can take revenge by using the robust, industriallooking tool. However, the tool can also be used by sad children to make themselves happy again. As children would not be inclined to use a punishment tool on themselves, the hypnosis machine can be interpreted as a restorative tool, rather than a punishment tool. Its main goal is to make children forget why they are sad or why they laugh at others. In this sense, the orientational positioning of the tool as a device for self-regulation is an important aspect only elaborated on in the team's presentation.

In the evolution from initial ideas to artifact, the role of the authoritative figure (Batman preventing children laughing at others and a hypnotized teacher telling jokes) shifted towards self-regulation. The regulatory role of adults in the initial ideas disappeared in favor of a more central role for children. This is a significant orientational shift from top- down towards bottom-up regulation in the co-design outcome. The team did, however, leave some room for third-party authority: the teacher can still intervene when a bully does not want to be hypnotized. In this teacher intervention, the external authority in the original idea returns, but only as a back-up when self-regulation fails. In sum, the Hypnosis Machine is a self-regulation tool to be used by individual children in problematic situations: it solves problems between bullies and their victims, and can make individual sad children happy again.

Organizationally, the team's presentation confirmed the visual elaboration of the artifact: the material and verbal modes reinforce each other in stressing the artifact's qualities as a tool. Moreover, the Machine can be seen as one tool integrating solutions to two quite different problems: being sad (for reasons that are not made explicit) and being bullied. It is not just a tool with two different functionalities to solve two different problems: the same functionality can be used to solve both problems. Organizationally, this is a very tight integration of the double problem definition. As a deus ex machina, the Hypnosis Machine resolves the problems magically and immediately. 


\subsubsection{DISTILLING DISCOURSE AND VALUES}

The design features of the hypnosis machine point towards a very functional design intended to be used by individuals. Orientationally, the focus is on the bullying victim, the perpetrator, and the sad child. The rest of the class group is not focused on, and the teacher only intervenes when the self-regulation among the children fails. This shows that the co-design team mainly promoted values of 'self-regulation' and 'victim empowerment', only regulated top-down when things tend to go wrong (e.g. a bully not wanting to be hypnotized). The hypnosis solution, however, does not include social processes of restoration, which in a reallife situation would be necessary. While these social processes are shut out, the tool enables both bully and victim to forget and move forward, rather than to relive the past and to look for someone to blame. This 'motivated' or 'directed' forgetting enables children to start with a clean sheet without an ongoing social process of reconciliation. The tool should therefore be seen as the embodiment of a positive solution to problems in the classroom. Compared to our initial values, the analysis of the hypnosis machine points towards a strong focus on intervention, rather than prevention. However, as its ultimate goal is empowering its users to resolve conflicts themselves in a blameless, immediate way, the emphasis of team Samenwerkers is on values of self-regulation, empowerment, and positivity (no blame).

\subsection{OUTCOME 3: THE WIZARD UKI}

\subsubsection{GROUNDING THE ANALYSIS}

The 'Ukis'- team translated the design challenge in two problems (see section 4.2): (1) children who brag and (2) children who fight and beat one another. Before the creation of the artifact, they had various initial ideas to solve the problematic situations and improve the class atmosphere. The team started out with an overweight of neutral ideas compared to negative, disciplinary and positive, preventive ideas ( 7 versus 5 and 3; some of the negative ideas are borderline cases). From the pool of ideas they had come up with during brainstorming, the team members collaboratively selected two ideas for further elaboration. For the first problem, children who brag, the team selected a positive, preventive idea as most promising: "showing that bragging is not good". For the second problem, children who fight and beat one another, they chose a positive, preventive idea as well: "saving someone". As such, the team started out with an overweight of neutral ideas, but eventually selected two positive, preventive ideas for further elaboration. 


\subsubsection{LISTING DESIGN FEATURES}

Starting from their original ideas, the team invented a human-like figure: a wizard with the name Uki (see Figure 5). During their presentation, children explained that during breaks, wizard Uki takes off and flies over the playground to watch children play. Children who do not behave as expected (e.g. bragging and fighting) will be transformed into a frog.

This team's artifact has a lot of human-like features (e.g. facial expression, arms, name, etc.). Each detail was discussed in the verbal explanation of the artifact, many of which had a clear purpose beyond decoration: the magic wand is used to transform bad children into frogs, the arrows indicate whether Uki is ready for take off and with the star on its pointy hat, Uki observes children during breaks. However, while every functional detail of Uki was discussed during the presentation (punishing children by turning them into a frog; controlling children by flying over the playground), his general aesthetics (the non-functional features, such as a green cape and a white hat, speckled with red stars) were left undiscussed.

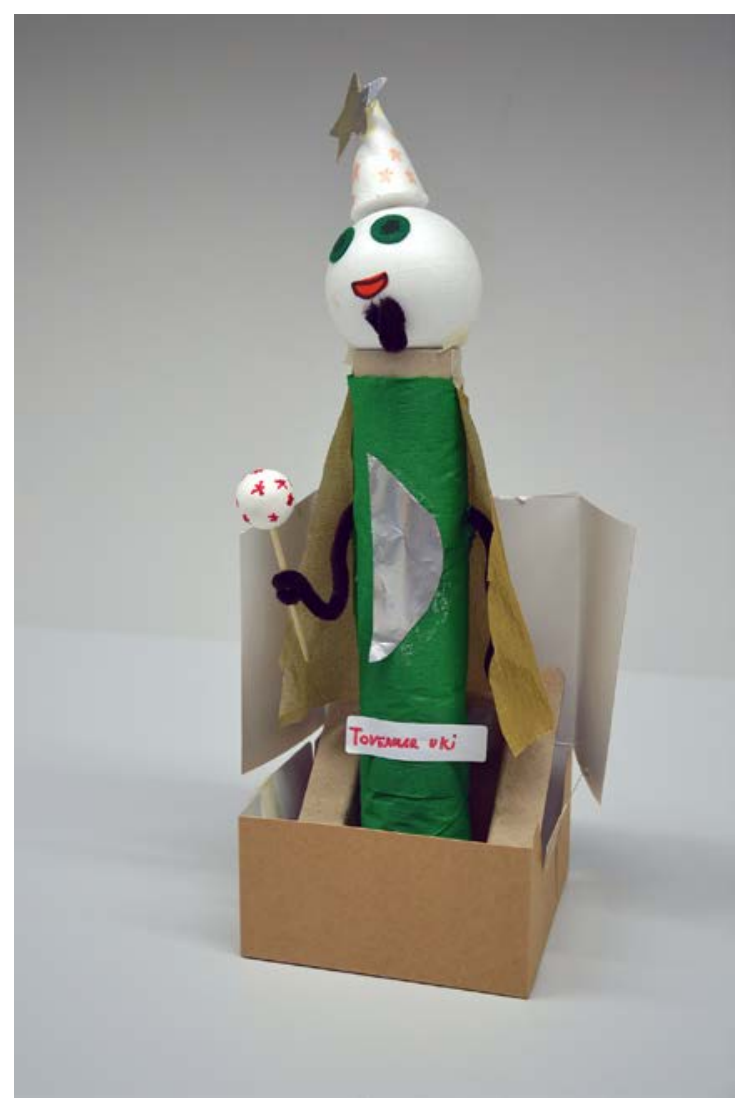

Figure 5: the wizard 'Uki' designed by team 'Ukis' 
At the end of their presentation, the children explained that that the wizard does not really turn children into frogs, and does not really fly over the playground. Instead, the wizard is a toy, to facilitate a role-playing game between victim and perpetrator. This role-playing game provides a clear rationale for the cheerful, non-threatening looks of Uki. In this sense, the verbal mode (the story about the role play) is complementary with the material mode (Uki as a smiling, non-threatening wizard).

\subsubsection{INTERPRETING ORIENTATION AND ORGANIZATION}

Orientationally, a distinction can be made between Uki's role as a toy mediating between victim and perpetrator on the one hand, and his role within the role-playing game itself. Within the game, wizard Uki has a supervisory and punishing role: nothing goes unnoticed because of the star on his head. While observing the children, Uki makes a clear distinction between good and bad behavior. Perpetrators are in the center of his attention, whereas victims and bystanders seem to be neglected. Perpetrators, when spotted, are turned into frogs as a form of punishment. However, as a toy mediating between victim and perpetrator, Uki's role changes: Uki no longer has agency but aims to empower victims in a playful manner. Victims use the toy to initiate restorative practices with their perpetrators. Through a role-playing game in which the wizard transforms the perpetrator into a frog, the perpetrator comes to realize the effects of his or her behavior on the victim. The spell can only be broken if the perpetrator changes his or her behavior for the better. Although the game is centered on punishment, the eventual goal is to reconnect victim and perpetrator, using the role-play during the process of reconciliation.

Organizationally, the initial punishing, controlling tone of the co-design team's explanation contrasts with the general aesthetics of the wizard. Uki looks cheerful and a lot of effort was put in decorative details such as a pointed hat with a star, a magic wand and a long green cape. His white hat and wand, speckled with red stars, and his green dress create an overall friendly, non-threatening look. Moreover, the wizard looks friendly: he has a smile on his face, and a small beard. The look of the wizard was commented upon by children from other teams, who called the wizard pretty. However, Uki's role as a role-playing toy resolves the apparent mismatch between the wizard's looks and the punishing, controlling role. In this light, the apparent paradox between Uki's cheerful appearance and his disciplinary, authoritative role is resolved. 
The solutions for the two initial design problems (bragging and fighting) have been merged into one wizard. Uki does not really have attributes that addresses either of the issues directly. Rather, the solution to the bragging problem (showing that bragging is not good) has been extended to a general reconciliation through a role-play in which victims can bring perpetrators to new insights in a playful and friendly way, showing that all kinds of bullying behavior is not good. The solution to the fighting and beating problem initially was in saving someone. This solution is embedded within the fictional world of the role play: the children talked about how bullies can no longer hit anyone because they have been turned into a frog. Outside of the fictional world, however, the team's solution to the fighting and beating problem also comes down to the role play: "you show that that [behavior] is not good, by saying: he did something [bad], and now he is a frog, and then you say: I'll set you free if you never do it again. [...] Then he [the perpetrator] also knows that that is not good, and he doesn't like it himself."

Uki's cheerful appearance highlights or gives special weight to this playful layer, an aspect that was somewhat underexposed in the presentation, where the content of the game (turning bullies into frogs, etc.) was stressed. In sum, Uki embodies a generic solution that can solve different types of problematic behavior, including the two original design problems.

\subsubsection{DISTILLING DISCOURSE AND VALUES}

The team proposed an anthropomorphic figure, a wizard, that can supervise children, and influence their behavior. The analysis of the design features showed that although the content of the role-playing game is centered on punishment, the main aim of the game is to reconcile perpetrator and victim. This reconciliation game is seen as a generic solution to different types of problematic behavior. Orientationally, this makes Uki a tool for restorative practices through empowerment of the victim. Taken together, Uki presents a mixed combination of values. In the fictional world of the game, 'supervision' and 'punishment' are key values of the team's understanding of how tackle bullying behavior, bragging and fighting. However, through the role-playing game, values of 'empowerment', 'restoration', and, ultimately, 'fun', become key aspects. Compared to our initial set of values, Uki aligns well with the values of self-regulation - through victim empowerment - and a safe environment - the role playing game as a safe environment for reconciliation. The aspect of prevention, how- 
ever, is less present in Uki, as the 'in-game' values of supervision and punishment are embedded in a narrative of reconciliation and restoration.

\section{DISCUSSION}

To illustrate the GLID method, this paper discussed a case study in which children aged 9 to 10 were involved in a series of co-design activities. The aim was to generate ideas for future technologies and practices that would cope with bullying behavior in school. The co-design techniques served as constructivist tools to assist investigations of 'what may be' rather than simply 'what is' (Lee, 2014). The simultaneous act of making and reflection in the co-design activities increased children's awareness about the complexity of bullying behavior and how to establish and maintain a good class atmosphere.

Although children negotiated a solution with their team members while being engaged in making activities, they did not explicitly discuss personal values and value trade-off processes. This may at least partly be due to children's developmental characteristics. The participants were 9 to 10 years old and although they were verbal and self-reflective enough to discuss what they were thinking, according to Piaget children's abstract thinking skills are only beginning to develop at this age (Piaget, 1970). This implies that, when it comes to abstract concepts such as 'values', 9- to 10-year-olds may still have a difficult time verbalizing their thoughts and much of what they say needs to be interpreted within the context of concrete experiences (Piaget, 1970).

Co-design techniques proved to be particularly useful here, because the making activities stimulated ad hoc reflection and children did not have to think about complex and abstract issues without specific reference materials. In addition, since values are critical motivators for people's attitudes and behavior (Rokeach, 1973; Schwartz, 1992), the way in which children approached the design challenge and co-constructed a solution told us something about their values. The artifact and its verbal explanation were the result of a collective sense-making process in which children's negotiated values were embedded, be it implicitly. With GLID, we were able to combine both modes of communication (i.e., artifacts and verbal information) in a coherent analysis in order to arrive at a situated understanding of the values that underpin these co-design outcomes. 
The results showed that some of the team's ideas and suggestions are not very realistic (e.g. the hypnosis machine) or hard to reconcile with educational goals (e.g. directed forgetting as opposed to restorative practices). In addition, some co-design teams proposed design ideas that seem contradictory at first sight (e.g. victims turning bullies into frogs vs. a robot that listens to what both victim and perpetrator have to say). Combining these different suggestions into a holistic design in the further design process is challenging. However, by looking at the values embedded in co-design outcomes with GLID, we could go beyond the surface level of children's ideas and whether or not these ideas were realistic or justifiable from an educational perspective.

GLID furthermore enabled us to identify potential value conflicts between teams and other stakeholder groups. While we, as researchers, initially focused on values of prevention and self-regulative behavior to create a safe class environment, most co-design teams combined prevention and intervention measures into one integrated approach. The teams also hinted at a mix of top-down and bottom-up regulation to safeguard a positive atmosphere, yielding a different view on how to empower children. As for the teams' emphasis on positive reconciliation within a no-blame atmosphere, this aligned well with our goal to create a safe and positive environment for children. In this sense, the analysis of co-design outcomes extended and refined our understanding of how bullying can be combated in the social context of the classroom. Although a detailed comparative analysis between the co-design teams, and between co-design teams and other stakeholder groups is beyond the scope of this paper, we see it as a main strength of the GLID method. Such a comparative analysis also offers interesting opportunities to debrief children about the results.

In sum, with GLID, design researchers can identify values and potential value conflicts between children and other stakeholders. This type of knowledge is useful to more accurately define the design problem and gain insight in the impact of potential solutions on the lives and environment of children. However, since GLID is time consuming, design researchers looking for inspiration in the form of workable design ideas are advised to take a descriptive perspective (see section 2.1.1) to analyzing co-design outcomes.

In the case study described in this article, GLID was not applied as a single method-formula or a generic process. Rather, GLID served as a reflective tool that was carefully adapted to the context, including our own values. For instance, in the grounding stage, children's ideas were analyzed and categorized in terms of the values prevention, self-regulation and safe 
environment, resulting in the categories 'positive or preventive', 'negative or disciplinary' and 'neutral' ideas. These values not only permeated the grounding step but all four steps of the analysis. Since the process of interpretation is not value free, multiple and equally valid interpretations can co-exist. This means that, when other researchers would have used GLID to analyze the data, it could have resulted in different readings. GLID does not want to scientize this process in a positivistic sense, but aims to increase rigor and transparency by gradually constructing interpretations in a well-substantiated manner.

As multimodal analyses in modes of communication and metafunctions can be applied to all types of communication, the GLID method can be used to analyze the outcomes of various types of co-design processes. For instance, the method can also be used in cases where the co-design outcomes take other forms besides tangible outcomes. In this paper, we focused on the material and verbal modes, but other modes can be included as well to arrive at a coherent understanding (e.g. embodiment, process of negotiating meaning). When analyzing co-design outcomes with GLID, it is essential to pay attention to an appropriate selection of modes, and to analyze how these modes co-construct the co-design outcome, how they emphasize or downplay specific aspects of the design, and how this design as a whole mediates between different actors. Using the GLID method in other co-design contexts, with other types of co-design outcomes, however, remains an area for future work.

\section{CONCLUSION}

In this paper, the GLID method was presented to analyze co-design outcomes in a transparent and systematic way. GLID aims to deduce negotiated values embedded in co-design outcomes by integrating different modes of communication (e.g. verbal, material) in a coherent analysis. GLID thereby addresses two shortcomings found in academic literature: (1) a unilateral focus on the verbal explanation while neglecting the material dimensions of codesign artifacts, and (2) a lack of transparency when interpreting children's contributions.

Relying on GLID, first, the co-design outcomes are situated against the background of the participants' initial suggestions (Grounding). Next, all design features and their immediate functional consequences are listed in detail, providing a basic overview (Listing). Afterwards, these features are interpreted on an orientational and organizational level (Interpreting). Finally, the discourse and underlying values are analyzed (Distilling). Deducing these values is not a linear deductive process, but an interpretative process that involves several iterations 
of going back and forth between the different steps. Whereas the first two steps of the GLID method are more descriptive in nature, the final two steps are the most interpretative ones. Using GLID, a situated understanding of children's values is achieved, because the values can be traced back to their origins, that is, certain functionalities and their desired consequences. At the same time, by going beyond the surface level of ideas, a level of abstraction is added to the analysis, resulting in a rich and empathic understanding of what genuinely drives and motivates children.

We call upon researchers within the PD and CCI community to apply and validate the GLID method in different types of design projects. These applications will help us to critically examine and further refine the GLID method.

\section{ACKNOWLEDGMENTS}

This study is part of the EMSOC project, funded by IWT (Agency for Innovation by Science and Technology) and two PhD projects funded by Hasselt University and iMinds (Interdisciplinary institute for Technology), a research institute founded by the Flemish Government. The goal of EMSOC project is to critically assess the belief of the user being empowered in a social media culture. The research is structured according to three main areas of interest in society where user (dis)empowerment is taking place related to social computing: inclusion, literacy and privacy. An interdisciplinary team from Vrije Universiteit Brussel, Universiteit Gent and KU Leuven collaborate to provide well-funded answers to the challenging assumptions and principles of the EMSOC research project.

\section{REFERENCES}

Barker, C., Galasinski, D., 2001. Cultural Studies and Discourse Analysis: A Dialogue on Language and Identity. SAGE, London.

Bijker, W.E., Hughes, T.P., Pinch, T., 1985. The Social Construction of Technological Systems: New Directions in the Sociology and History of Technology. MIT Press, Cambridge, MA.

Brandt, E., Binder, T., Sanders, E.B.-N., 2013. Tools and techniques: Ways to engage telling, making and enacting, in: Routledge International Handbook of Participatory Design. Routledge, Oxford. 
Bratteteig, T., Bodker, K., Dittrich, Y., Holst, P., Simonsen, J., 2013. Methods: Organising Principles and General Guidelines for Participatory Design Projects, in: Routledge International Handbook of Participatory Design. Routledge, Oxford.

Buckingham, D., 2009. 'Creative' visual methods in media research: possibilities, problems and proposals. Media Cult. Soc. 31, 633-652. doi:10.1177/0163443709335280

Cockton, G., 2004. Value-centred $\mathrm{HCl}$, in: Proceedings of the Third Nordic Conference on Human-Computer Interaction, NordiCHI '04. ACM, New York, NY, USA, pp. 149-160. doi:10.1145/1028014.1028038

Derboven, J., Van Mechelen, M., Slegers, K., 2015. Multimodal Analysis in Participatory Design with Children: A Primary School Case Study, in: Proceedings of the 33rd Annual ACM Conference on Human Factors in Computing Systems, CHI '15. ACM, New York, NY, USA, pp. 2825-2828. doi:10.1145/2702123.2702475

Dindler, C., Eriksson, E., Iversen, O.S., Lykke-Olesen, A., Ludvigsen, M., 2005. Mission from Mars: A Method for Exploring User Requirements for Children in a Narrative Space, in: Proceedings of the 2005 Conference on Interaction Design and Children, IDC' 05. ACM, New York, NY, USA, pp. 40-47. doi:10.1145/1109540.1109546

Dindler, C., Iversen, O.S., Smith, R., Veerasawmy, R., 2010. Participatory Design at the Museum: Inquiring into Children's Everyday Engagement in Cultural Heritage, in: Proceedings of the 22Nd Conference of the Computer-Human Interaction Special Interest Group of Australia on Computer-Human Interaction, OZCHI '10. ACM, New York, NY, USA, pp. 72-79. doi:10.1145/1952222.1952239

Donoso, V., Van Mechelen, M., Verdoodt, V., 2014. Increasing User Empowerment through Participatory and Co-design Methodologies. KU Leuven.

Druin, A., 1999. Cooperative Inquiry: Developing New Technologies for Children with Children, in: Proceedings of the SIGCHI Conference on Human Factors in Computing Systems, CHI '99. ACM, New York, NY, USA, pp. 592-599. doi:10.1145/302979.303166

Ehn, P., 1993. Scandinavian design: on participation and skill, in: Participatory Design - Principles and Practices. Lawrence Erlbuam Aoociates, Hillsdale, NY, pp. 41-70.

Fleischmann, K., 2014. Information and Human Values. Morgan \& Claypool.

Frauenberger, C., Good, J., Fitzpatrick, G., Iversen, O.S., 2015. In pursuit of rigour and accountability in participatory design. Int. J. Hum.-Comput. Stud. 74, 93-106. doi:10.1016/j.ijhcs.2014.09.004

Frauenberger, C., Good, J., Keay-Bright, W., Pain, H., 2012. Interpreting Input from Children: A Designerly Approach, in: Proceedings of the SIGCHI Conference on Human Factors in Computing Systems, CHI '12. ACM, New York, NY, USA, pp. 2377-2386. doi:10.1145/2207676.2208399

Friedman, B., Kahn, P.H., Borning, A., 2006. Value Sensitive Design and Information Systems, in: Human-Computer Interaction in Management Information Systems: Foundations. M.E. Sharpe, Inc, New York.

Gielen, M.A., 2008. Exploring the child's mind - contextmapping research with children. Digit. Creat. 19, 174-184. doi:10.1080/14626260802312640

Gielen, M.A., 2007. What's on a child's mind: Contextmapping research for designers' inspiration. Presented at the 1st International Symposium on Ludic Engagement Designs for All, Aalborg University, Esbjerg, pp. 26-29.

Guha, M., Druin, A., Fails, J., 2013. Cooperative Inquiry Revisited: Reflections of the Past and Guidelines for the Future of Intergenerational Co-design. Int. J. Child-Comput. Interact. Volume 1, $14-23$.

Gutman, J., 1982. A Means-End Chain Model Based on Consumer Categorization Processes. J. Mark. 46, 60-72. doi:10.2307/3203341

Halliday, M.A.K., 1978. Language as a Social Semiotic: The Social Interpretation of Language and Meaning. University Park Press. 
Halloran, J., Hornecker, E., Stringer, M., Harris, E., Fitzpatrick, G., 2009. The value of values: Resourcing co-design of ubiquitous computing. CoDesign 5, 245-273. doi:10.1080/15710880902920960

Hodge, B., Kress, G., 1988. Social Semiotics. Polity Press, Cambridge, UK.

Horton, M., Read, J.C., Mazzone, E., Sim, G., Fitton, D., 2012. School Friendly Participatory Research Activities with Children, in: $\mathrm{CHI}$ '12 Extended Abstracts on Human Factors in Computing Systems, CHI EA '12. ACM, New York, NY, USA, pp. 2099-2104. doi:10.1145/2212776.2223759

Iversen, O.S., Halskov, K., Leong, T.W., 2012. Values-led participatory design. CoDesign 8, 87-103. doi:10.1080/15710882.2012.672575

Iversen, O.S., Halskov, K., Leong, T.W., 2010. Rekindling Values in Participatory Design, in: Proceedings of the 11th Biennial Participatory Design Conference, PDC'10. ACM, New York, NY, USA, pp. 91-100. doi:10.1145/1900441.1900455

Iversen, O.S., Leong, T.W., 2012. Values-led Participatory Design: Mediating the Emergence of Values, in: Proceedings of the 7th Nordic Conference on Human-Computer Interaction: Making Sense Through Design, NordiCHI '12. ACM, New York, NY, USA, pp. 468-477. doi:10.1145/2399016.2399087

JafariNaimi, N., Nathan, L., Hargraves, I., 2015. Values as Hypotheses: Design, Inquiry, and the Service of Values. Des. Issues 31, 91-104. doi:10.1162/DESI_a_00354

Jewitt, C., 2013. Multimodal Methods for Researching Digital Technologies, in: The SAGE Handbook of Digital Technology Research. SAGE, London, pp. 250-265.

Jewitt, C., 2010. An Introduction to Multimodality, in: The Rootledge Handbook of Multimodal Analysis. Routledge, London, pp. 14-27.

Knudtzon, K., Druin, A., Kaplan, N., Summers, K., Chisik, Y., Kulkarni, R., Moulthrop, S., Weeks, H., Bederson, B., 2003. Starting an Intergenerational Technology Design Team: A Case Study, in: Proceedings of the 2003 Conference on Interaction Design and Children, IDC '03. ACM, New York, NY, USA, pp. 51-58. doi:10.1145/953536.953545

Kress, G., 2010. Multimodality: A Social Semiotic Approach to Contemporary Communication. Routledge, London.

Lee, J.-J., 2014. The True Benefits of Designing Design Methods. Artifact 3, 5-1-5.12. doi:10.14434/artifact.v3i2.3951

Lemke, J.L., 2002. Travels in Hypermodality. Vis. Commun. 1, 299-325.

Malinverni, L., Mora-Guiard, J., Pares, N., 2016. Towards methods for evaluating and communicating participatory design: A multimodal approach. Int. J. Hum.-Comput. Stud. doi:10.1016/j.ijhcs.2016.03.004

Mazzone, E., Read, J., Beale, R., 2008. Understanding Children's Contributions During Informant Design, in: Proceedings of the 22Nd British $\mathrm{HCl}$ Group Annual Conference on People and Computers: Culture, Creativity, Interaction - Volume 2, BCS-HCl '08. British Computer Society, Swinton, UK, UK, pp. 61-64.

Moser, C., 2012. Child-centered game development (CCGD): developing games with children at school. Pers. Ubiquitous Comput. 17, 1647-1661. doi:10.1007/s00779-012-0528-z

Muller, M.J., 2002. Participatory Design: The Third Space in $\mathrm{HCl}$, in: Jacko, J.A., Sears, A. (Eds.), The Human-Computer Interaction Handbook. L. Erlbaum Associates Inc., Hillsdale, NJ, USA, pp. 1051-1068.

Piaget, J., 1970. Science of Education and the Psychology of the Child. Penguin Books.

Piper, H., Frankham, J., 2007. Seeing Voices and Hearing Pictures: Image as discourse and the framing of image-based research. Discourse Stud. Cult. Polit. Educ. 28, 373-387. doi:10.1080/01596300701458954

Polanyi, M., 1983. The Tacit Dimension. Peter Smith, Gloucester, MA. 
Read, J.C., Fitton, D., Horton, M., 2014. Giving Ideas an Equal Chance: Inclusion and Representation in Participatory Design with Children, in: Proceedings of the 2014 Conference on Interaction Design and Children, IDC'14. ACM, New York, NY, USA, pp. 105114. doi:10.1145/2593968.2593986

Read, J.C., Horton, M., Sim, G., Gregory, P., Fitton, D., Cassidy, B., 2013. CHECk: A Tool to Inform and Encourage Ethical Practice in Participatory Design with Children, in: $\mathrm{CHI}$ '13 Extended Abstracts on Human Factors in Computing Systems, CHI EA '13. ACM, New York, NY, USA, pp. 187-192. doi:10.1145/2468356.2468391

Read, J.C., Markopoulos, P., 2013. Child-computer interaction. Int. J. Child-Comput. Interact. $1,2-6$.

Reynolds, T.J., Gutman, J., 1988. Laddering theory, method, analysis, and interpretation. J. Advert. Res. 28, 11-31.

Rokeach, M., 1973. The Nature of Human Values. Free Press, New York - London.

Sanders, E.B.-N., 2002. From User-Centered to Participatory Design Approaches, in: Design and the Social Sciences. Taylor \& Francis Books Limited, Oxford.

Sanders, E.B.-N., 2000. Generative Tools for CoDesigning, in: Collaborative Design. SpringerVerlag, London.

Sanders, E.B.-N., 1999. Postdesign and Participatory Culture. Presented at the Proceedings of the International Conference "Useful and Critical: The Position of Research in Design," Helsinki.

Sanders, E.B.-N., 1992. CONVERGING PERSPECTIVES: Product Development Research for the 1990s. Des. Manag. J. Former Ser. 3, 49-54. doi:10.1111/j.19487169.1992.tb00604.x

Sanders, E.B.-N., Stappers, P.J., 2008. Co-creation and the new landscapes of design. CoDesign 4, 5-18. doi:10.1080/15710880701875068

Sanders, E.B.-N., William, C.T., 2001. Harnessing People's Creativity: Ideation and Expression through Visual Communication, in: Focus Groups: Supporting Effective Product Development. Taylor \& Francis Group, Abingdon.

Sanders, L., Simons, G., 2009. A Social Vision for Value Co-creation in Design. Open Source Bus. Resour.

Scaife, M., Rogers, Y., 1999. Kids as informants: telling us what we didn't know or confirming what we knew already?, in: The Design of Children's Technology: How We Design, What We Design, and Why. Morgan Kaufman.

Scaife, M., Rogers, Y., Aldrich, F., Davies, M., 1997. Designing for or Designing with? Informant Design for Interactive Learning Environments, in: Proceedings of the ACM SIGCHI Conference on Human Factors in Computing Systems, CHI '97. ACM, New York, NY, USA, pp. 343-350. doi:10.1145/258549.258789

Schuler, D., Namioka, A. (Eds.), 1993. Participatory Design: Principles and Practices. L. Erlbaum Associates Inc., Hillsdale, NY.

Schwartz, S.H., 1992. Universals in the content and structure of values: theoretical advances and empirical tests in 20 countries, in: Advances in Experimental Social Psychology. Academic Press, New York, pp. 1-65.

Sengers, P., Boehner, K., David, S., Kaye, J. "Jofish," 2005. Reflective Design, in: Proceedings of the 4th Decennial Conference on Critical Computing: Between Sense and Sensibility, CC'05. ACM, New York, NY, USA, pp. 49-58. doi:10.1145/1094562.1094569

Sleeswijk Visser, F.S., Stappers, P.J., Van, R., Lugt, D., Sanders, E.B.-., 2005. Contextmapping: Experiences from Practice. CoDesign 1, 149.

Stappers, P.J., Sanders, E.B.-N., 2003. Generative Tools for Contextmapping: Tuning the Tools. Presented at the Proceedings of the Third International Conference on Design and Emotion, Loughborough. 
Vanden Abeele, V., Zaman, B., Grooff, D.D., 2011. User eXperience Laddering with preschoolers: unveiling attributes and benefits of cuddly toy interfaces. Pers. Ubiquitous Comput. 16, 451-465. doi:10.1007/s00779-011-0408-y

Van Doorn, F., Stappers, P.J., Gielen, M., 2013. Design Research by Proxy: Using Children As Researchers to Gain Contextual Knowledge About User Experience., in: Proceedings of the SIGCHI Conference on Human Factors in Computing Systems, CHI '13. ACM, New York, NY, USA, pp. 2883-2892. doi:10.1145/2470654.2481399

Van Leeuwen, T., 2005. Introducing Social Semiotics. Routledge, London.

Van Mechelen, M., Derboven, J., 2014. Multimodal Analysis of Participatory Design Results. Presented at the Proceedings of the NordiCHI 2014 workshop "The Fuzzy Front End of Experience Design," VIT Technical Research Centre of Finland Ltd.

Van Mechelen, M., Gielen, M., Vanden Abeele, V., Laenen, A., Zaman, B., 2014a. Exploring Challenging Group Dynamics in Participatory Design with Children, in: Proceedings of the 2014 Conference on Interaction Design and Children, IDC'14. ACM, New York, NY, USA, pp. 269-272. doi:10.1145/2593968.2610469

Van Mechelen, M., Sim, G., Zaman, B., Gregory, P., Slegers, K., Horton, M., 2014b. Applying the CHECk Tool to Participatory Design Sessions with Children, in: Proceedings of the 2014 Conference on Interaction Design and Children, IDC '14. ACM, New York, NY, USA, pp. 253-256. doi:10.1145/2593968.2610465

Van Mechelen, M., Zaman, B., Laenen, A., Vanden Abeele, V., 2015. Challenging Group Dynamics in Participatory Design with Children: Lessons from Social Interdependence Theory, in: Proceedings of the 14th International Conference on Interaction Design and Children, IDC'15. ACM, New York, NY, USA, pp. 219-228. doi:10.1145/2771839.2771862

Veale, A., 2005. Creative Methodologies in Participatory Research with Children, in: Researching Children's Experience. SAGE Publications Ltd, London - Thousand Oaks New Delhi.

Zaman, B., Vanden Abeele, V., 2010. Laddering with Young Children in User eXperience Evaluations: Theoretical Groundings and a Practical Case, in: Proceedings of the 9th International Conference on Interaction Design and Children, IDC'10. ACM, New York, NY, USA, pp. 156-165. doi:10.1145/1810543.1810561

Zhao, S., Djonov, E., Van Leeuwen, T., 2014. Semiotic Technology and Practice: a Multimodal Social Semiotic Approach to PowerPoint. Text Talk 34, 349-375. 

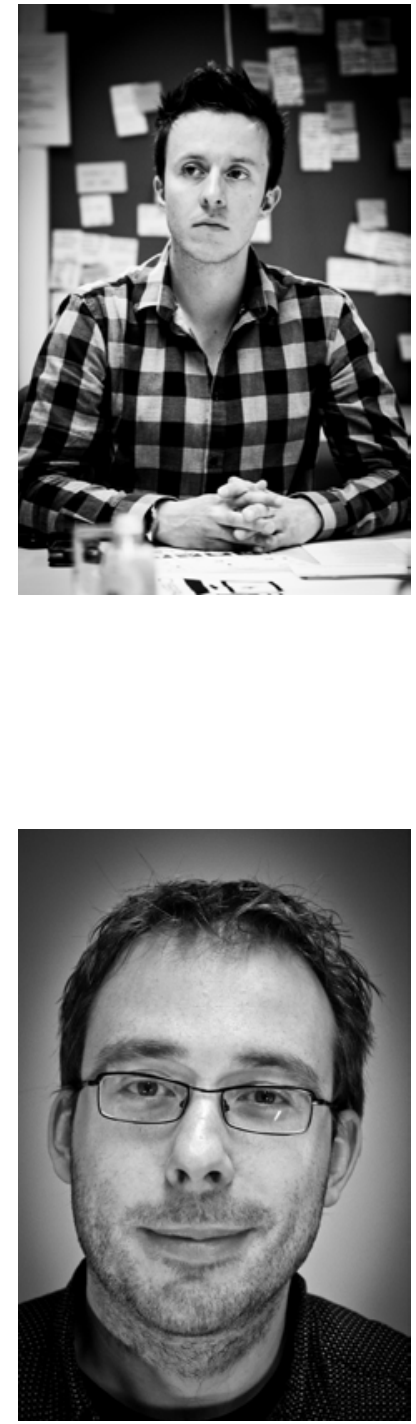

Jan Derboven (jan.derboven@soc.kuleuven.be, www.cuo.be) graduated as a Master in Germanic Languages (KU Leuven, 2002) and in Cultural Studies (2003). He is a senior researcher at the Meaningful Interactions Lab (KU Leuven - iMinds), where his research is situated primarily in the domains of media (technology, games \& education) and health (assistive technologies). Currently, he is pursuing a PhD on technology appropriation, investigating how people use and reinterpret technologies in everyday life.

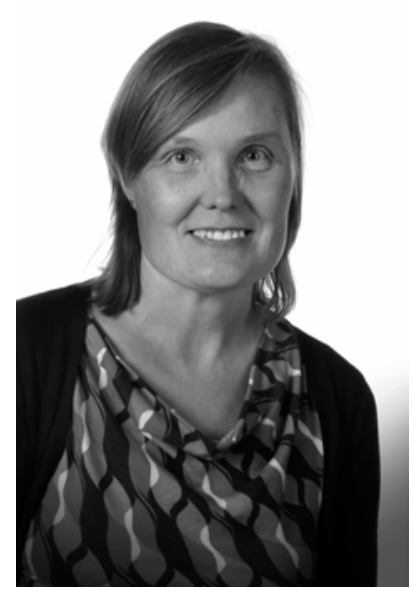

Ann Laenen studied Arts and Theatre Science and reached PhD level in 2007 on Arts Education. In 2009 she became the co-ordinator of the Communication Media Design - programme at the Media \& Design Academy in Genk. October 2010 she became the Head of Department at that institution and two years later she was appointed Dean of the Faculty of the Arts (LUCA School of Arts / KU Leuven). Her research focus today is on arts/design education and interactive processes. At present she is teaching Active Design Processes at the Department of Digital Arts (University of Malta). 

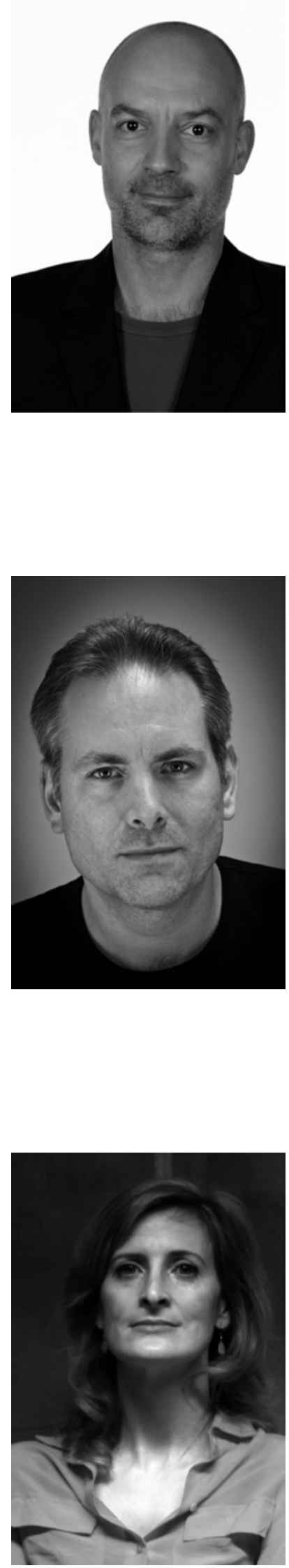

Vero Vanden Abeele is assistant professor at the e-Media Lab of KU Leuven. Vero is active in the area of persuasive computing and serious games. Vero's specialties include among many: user experience research, human-computer interaction, player experience, usability, playability, interaction design, tangible play and motivational design. Vero is member of several program committees (ACM International Conference on Interaction Design and Children), ACM Conference on Computer-Human Interaction, ACM International Conference on Tangible, Embodied and Embedded interaction, ACM Conference on CHI Play) and has been a co-applicant for several national and international research projects concerning serious games and children. 